\title{
Development of acute feeding disorders, hyperactivity, and stomach pathology after medial and lateral hypothalamic lesions in rats
}

\author{
JOSÉ N. NOBREGA, NEIL I. WIENER, and KLAUS-PETER OSSENKOPP \\ York University, Downsview, Ontario M3J 1P3, Canada
}

\begin{abstract}
The acute effects of medial (VMH) and lateral (LH) hypothalamic lesions on stomach morphology, motor activity, and feeding behavior were compared in two experiments. Rats received $\mathrm{VMH}$ or LH lesions and were sacrificed 4,8 , or $24 \mathrm{~h}$ later. Both lesions produced high activity counts at $4 \mathrm{~h}$ and a comparable number of ulcers, starting at the earliest interval tested. Neither VMH nor LH lesions produced acute changes in other organs, such as the adrenals, thymus, or spleen. In a second experiment, quantitative measures of stomach pathology did not indicate significant differences between ulceration produced by VMH and LH lesions in $24 \mathrm{~h}$. A separate group receiving VMH lesions showed pronounced hyperphagia and hyperdipsia immediately after the lesion, while LH rats were aphagic and adipsic. Motor activity levels after the lesions correlated positively with ulcer incidence and severity. Possible relations between these acute behavioral and visceral effects of hypothalamic lesions are discussed.
\end{abstract}

Hypothalamic lesions can induce a number of autonomic and behavioral effects, including motor hyperactivity (Harrell \& Remley, 1973; Maire \& Patton, 1954; McGinty, 1969; Whishaw \& Robinson, 1974), alterations in feeding behavior (Harrell \& Remley, 1973; Schallert, Whishaw, \& Flannigan, 1977), gastric ulceration (Anderson \& Haymaker, 1974; Cushing, 1932; French, Porter, von Amerongen, \& Raney, 1952; Hoff \& Sheehan, 1935; Long, Leonard, \& French, 1962; Watts \& Fulton, 1935), and changes in pulmonary and cardiovascular functions (Maire \& Patton, 1954; Reis, Gauthier, \& Nathan, 1976). There is no generally accepted view of the relations among these various changes, not all of which necessarily result from the same hypothalamic lesion placements. In recent years, the fact that lesions of the lateral hypothalamus $(\mathrm{LH})$ that produce chronic aphagia and adipsia (Anand \& Brobeck, 1951; Teitelbaum \& Epstein, 1962) also produce stomach ulceration (Lindholm, Shumway, Grijalva, Schallert, \& Ruppel, 1975; Teitelbaum \& Epstein, 1962) has led to the suggestion that such lesion-induced gastric pathology

This research was supported by a grant from the National Research Council of Canada to Neil I. Wiener. Requests for reprints should be sent to N. I. Wiener, Department of Psychology, York University, Downsview, Ontario M3J 1P3, Canada. Portions of the data reported in this paper were presented at the 86th Annual Meeting of the American Psychological Association, Toronto, August 1978. We wish to thank Dr. G. B. Glavin for his comments on an earlier version of this paper. Klaus-Peter Ossenkopp, now at the University of Western Ontario, London, Ontario, was supported by a National Research Council of Canada Post-Graduate Scholarship. may contribute significantly to the feeding deficits that are characteristic of the LH syndrome (Grijalva, Lindholm, Schallert, \& Bucknell, 1976; Lindholm et al., 1975). Schallert et al. (1977) reported that LH lesions can produce aphagia and gastric pathology within $24 \mathrm{~h}$. However, these investigators also noted that some rats with high gastric pathology would eat dry food and that other rats were aphagic but had negligible gastric pathology, thus indicating a dissociation between gastric pathology and feeding deficits.

An important aspect to be considered in investigations of autonomic and behavioral effects of hypothalamic lesions is the time frame in which observations are carried out. It is known, for example, that stomach ulcers induced by hypothalamic lesions may heal within a few days (Luparello, 1967), although such ulcers have also been observed several weeks after hypothalamic lesions (French et al., 1952; Watts $\&$ Fulton, 1935). In the latter case, it is also conceivable that ulcers may take longer to develop after certain hypothalamic lesion placements than after others.

While lateral hypothalamic lesions can cause feeding deficits and stomach pathology within $24 \mathrm{~h}$ of the lesion (Schallert et al., 1977), the time course for the development of ulceration after medial hypothalamic lesions, which can induce eating early in the postoperative period (Harrell \& Remley, 1973), has not been determined.

The experiments reported here focused on the acute postoperative period. The purpose of the study was to compare some of the acute behavioral and visceral effects of lateral hypothalamic lesions to 
those induced by medial lesions in the same period, by monitoring the rate of development of such effects in the first $24 \mathrm{~h}$ after the lesions.

\section{EXPERIMENT 1}

In this experiment, the incidence and rate of development of gastric pathology after VMH and LH lesions were compared. In addition, since some of the acute effects of hypothalamic lesions, including gastric ulceration, also occur in the so-called alarm reaction of the general adaptation syndrome (Selye, 1946), it was decided to investigate the acute effects of VMH and $\mathrm{LH}$ lesions on three other organs that are known to undergo weight changes early in response to alarming stimuli in general, namely the adrenals, thymus, and spleen (Selye, 1946). Weight measurements of these organs at various intervals after VMH or LH lesions were done so as to obtain a first indication of the extent to which hypothalamic lesion-induced ulcers are simply part of a set of bodily reactions to injury in general, rather than being specifically associated with particular brain areas affected by the lesions.

\section{Method}

Animals. Male Wistar rats (Woodlyn Laboratories, Guelph, Ontario), weighing between 300 and $480 \mathrm{~g}$, were used. The animals were housed in groups of four in wire mesh cages with regular chow pellets and water ad lib. Lights were on between 0700 and 1900 h daily.

Surgery. The animals were food-deprived $24 \mathrm{~h}$ prior to the lesions and then anesthetized with sodium pentobarbital $(60 \mathrm{mg} / \mathrm{kg})$. No supplementary anesthesia was used, and no atropine or any other drug was given during or after surgery. Lesions were made by passing dc anodal 1-mA current for $20 \mathrm{sec}$ through a No. 00 stainless steel insect pin insulated with two coats of Epoxylite except for $.25 \mathrm{~mm}$ at the tip. The cathode was either inserted in the rectum or attached to the ear bars. Coordinates for lesions aimed at the ventromedial hypothalamus were $.2 \mathrm{~mm}$ anterior to bregma, $.8 \mathrm{~mm}$ lateral to the midline, and $9.0 \mathrm{~mm}$ from the skull surface (Pellegrino \& Cushman, 1967). Coordinates for lateral hypothalamic lesions were $1.4 \mathrm{~mm}$ posterior to bregma, $1.6 \mathrm{~mm}$ lateral to the midline, and $8.8 \mathrm{~mm}$ from the skull surface. All lesions were bilateral. Sham-operated controls were anesthetized and placed in the stereotaxic apparatus. The electrode was lowered bilaterally, but no current was passed. The animals were placed in individual cages after surgery.

Postoperative procedure. Since previous observation had indicated that some medial lesions often resulted in voracious eating soon after recovery from anesthesia, causing many animals to choke to death, food and water were withheld from all animals for the duration of the postoperative testing period. Animals receiving $\mathrm{VMH}, \mathrm{LH}$, or sham lesions were divided into three groups and sacrificed 4,8 , or $24 \mathrm{~h}$ after the lesions. Motor activity was measured by placing each animal in a $25 \times 30 \times 20 \mathrm{~cm}$ Plexiglas cage mounted on a stabilimeter (Lafayette Instruments No. 8610 activity platform). Activity counts were recorded for $15 \mathrm{~min}$ at $4 \mathrm{~h}$ after the lesions and again just prior to sacrifice for the 8- and 24-h groups.

The animals were sacrificed with ether. The stomach was tied at the two ends with surgical suture thread, removed, inflated with $.85 \%$ saline, and cut open along the greater curvature for visual inspection. The number, location, and general appearance of the observable pathology were recorded. In addition, the adrenal glands, thymus, and spleen were removed, separated from any attached adipose tissue, and immediately weighed on a Mettler H-16 scale.

After perfusion with saline and $10 \%$ Formalin, the brains were removed and stored in Formalin for at least 1 week. The brains were then frozen and 50-micron sections were mounted on microscope slides. These unstained sections were used as negatives in a photographic enlarger to obtain prints of the corresponding brain sections.

Data analysis. Multivariate analysis of variance followed by univariate ANOVAS and multiple comparisons or independent $t$ tests were performed, using lesion type and postoperative interval as factors and the following response variables: number of ulcers, activity counts, and weight of the adrenals, thymus, and spleen. Analyses were done with a modified version of the MANOVA computer program originally developed at the Psychometric Laboratory of the University of North Carolina.

\section{Results}

Lesion placements for all animals in the medial and lateral hypothalamic groups are shown in Figures 1 and 2 , respectively. As illustrated, not all medial lesions were confined to the VMH; other medial structures affected included the dorsomedial nucleus and the anterior hypothalamic area. In some cases, lesions extended laterally into the medial forebrain bundle area. Most of the lateral lesions encroached upon the zona incerta/medial lemniscus area immediately dorsal to the $\mathrm{LH}$; in three animals, the center of the lesion was just posterior to the caudal tip of the $\mathrm{LH}$.

As Table 1 indicates, stomach pathology was observed in all lesioned groups at all intervals tested, despite the small number of animals tested in each group. Electrode lowering did not result in visible pathology in any of the sham-operated control groups. No attempt was made to measure the size of ulcers in this experiment but, so far as could be determined by unaided visual inspection, no consistent differences were apparent between ulceration produced by medial and lateral lesions at the intervals tested, in terms of shape, overall size, and location in the stomach. Softening of the stomach, localized ischemia, and diffuse hemorrhage were not counted as pathology. Both medial and lateral hypothalamic lesions resulted in ulcers that were invariably restricted to the glandular portion of the stomach, were round or elongated in shape, and were filled with and/or surrounded by hemorrhage. Figure 3 depicts the typical appearance of the stomach of a VMH rat $24 \mathrm{~h}$ after the lesion.

Examination of the histological plates revealed no single, exclusive site within the hypothalamus where lesions resulted always in stomach pathology. Furthermore, while the analyses of variance comparisons showed the lesioned groups to differ significantly from the control group in terms of number of ulcers $[F(2,27)=7.14, p<.003]$, no such difference emerged in comparisons between the two lesioned groups along the time dimension $[F(2,27)=.1, p>.8]$. 


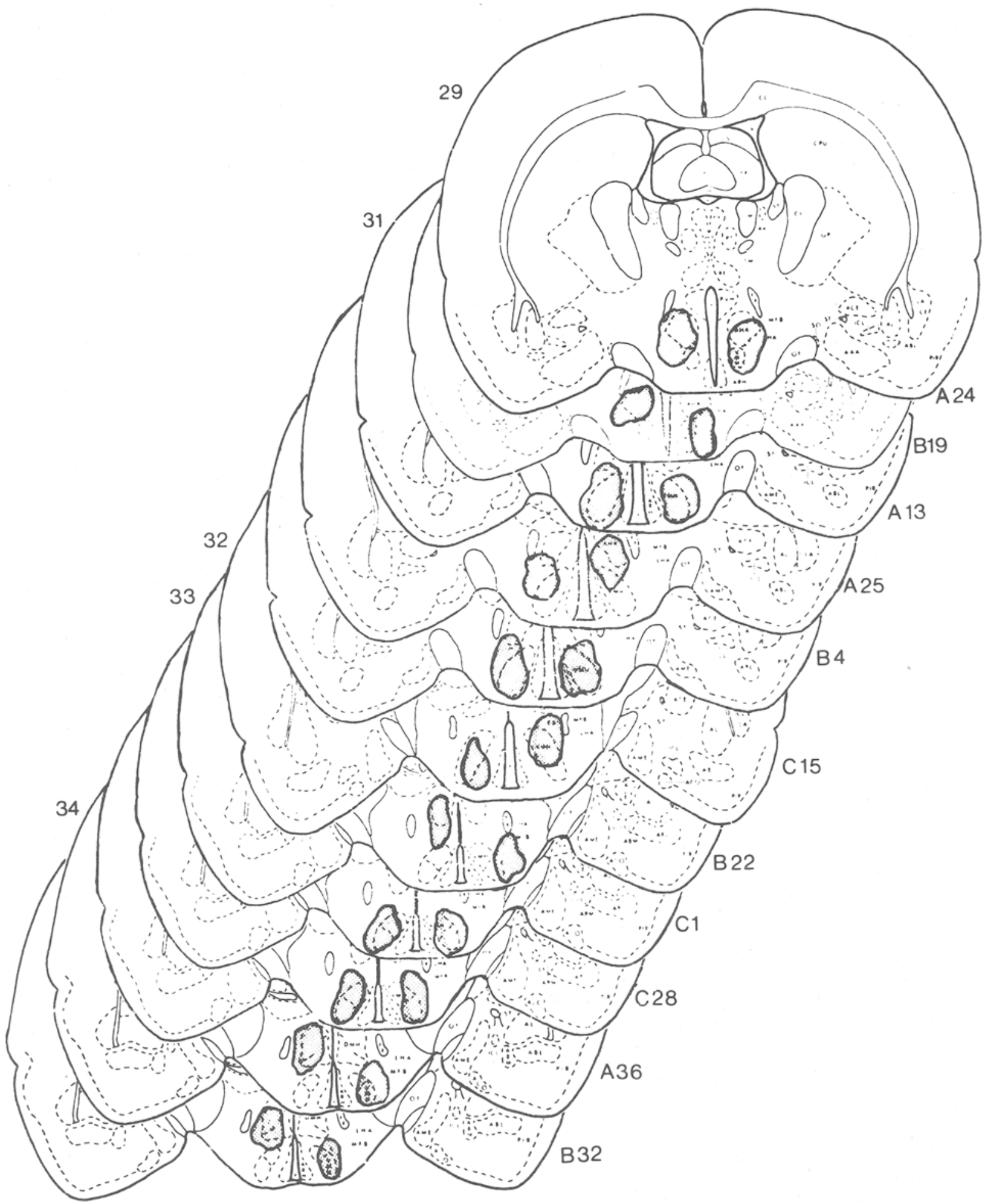

Figure 1. Semidiagramatic reconstruction of lesion placements for rats in the medial hypothalamic group in Experiment 1. Numbers to the left of each section indicate the corresponding plate of the Pellegrino and Cushman (1967) atlas. Unnumbered sections have the same number as the one immediately above them. The letters $A, B$, and $C$ in the animal identification codes on the lower right indicate whether the rats were sacrificed after $4 \mathrm{~h}(\mathrm{~A}), 8 \mathrm{~h}(\mathrm{~B})$, or $24 \mathrm{~h}$ (C). 


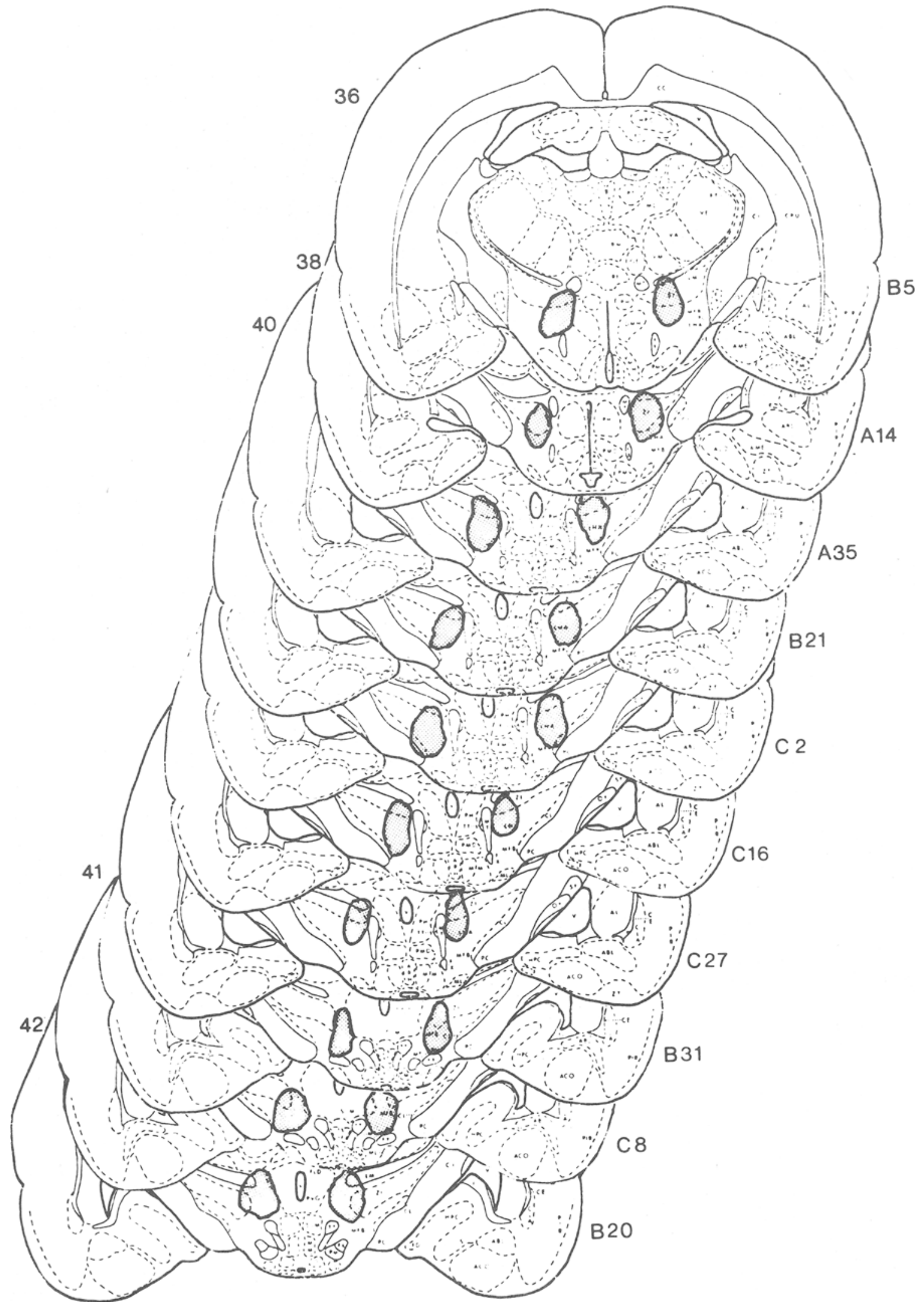

Figure 2. Semidiagramatic reconstruction of lesion placements for rats in the lateral hypothalamic group in Experiment 1. See legend for Figure 1. 
Table 1

Means and Standard Errors for Six Variables in Experiment 1

\begin{tabular}{|c|c|c|c|c|c|c|c|c|c|c|c|c|c|}
\hline \multirow[b]{3}{*}{ Group } & \multirow{3}{*}{$\begin{array}{c}\text { Test } \\
\text { Inter- } \\
\text { val } \\
\text { (h) }\end{array}$} & \multirow[b]{3}{*}{$\mathbf{N}$} & & & \multicolumn{6}{|c|}{ Weight (g) } & \multirow{2}{*}{\multicolumn{2}{|c|}{$\begin{array}{l}\text { Activity } \\
\text { Counts* }\end{array}$}} & \multirow{3}{*}{$\begin{array}{c}\text { Ulcer Inci } \\
\text { dence per } \\
\text { Group }\end{array}$} \\
\hline & & & \multicolumn{2}{|c|}{$\mathrm{N}$ of Ulcers } & \multicolumn{2}{|c|}{ Adrenals } & \multicolumn{2}{|c|}{ Thymus } & \multicolumn{2}{|c|}{ Spleen } & & & \\
\hline & & & $\mathbf{M}$ & $\mathrm{SE}$ & M & SE & M & SE & M & SE & M & SE & \\
\hline VMH & 4 & 4 & 3.00 & 1.77 & .022 & .001 & .270 & .053 & .545 & .041 & 1395 & 350 & $3 / 4$ \\
\hline VMH & 8 & 4 & 1.25 & .94 & .024 & .001 & .219 & .018 & .593 & .032 & 241 & 127 & $2 / 4$ \\
\hline VMH & 24 & 3 & 4.33 & 1.20 & .027 & .002 & .206 & .035 & .600 & .066 & 307 & 75 & $3 / 3$ \\
\hline $\begin{array}{l}\text { LH } \\
\text { LH }\end{array}$ & $\begin{array}{l}4 \\
8\end{array}$ & $\begin{array}{l}2 \\
4\end{array}$ & $\begin{array}{r}.50 \\
2.50\end{array}$ & $\begin{array}{r}.50 \\
1.55\end{array}$ & $\begin{array}{l}.023 \\
.024\end{array}$ & $\begin{array}{l}.001 \\
.001\end{array}$ & $\begin{array}{l}.332 \\
.248\end{array}$ & $\begin{array}{l}.027 \\
.019\end{array}$ & $\begin{array}{l}.552 \\
.613\end{array}$ & $\begin{array}{l}.047 \\
.050\end{array}$ & $\begin{array}{r}1228 \\
196\end{array}$ & $\begin{array}{l}392 \\
163\end{array}$ & $\begin{array}{l}1 / 2 \\
3 / 4\end{array}$ \\
\hline LH & 24 & 4 & .75 & .47 & .021 & .001 & .159 & .023 & .557 & .049 & 289 & 189 & $2 / 4$ \\
\hline Sham** & 4 & 6 & .00 & .00 & .022 & .001 & .242 & .035 & .616 & .036 & 70 & 30 & $0 / 6$ \\
\hline Sham & 8 & 4 & .00 & .00 & .020 & .001 & .237 & .034 & .599 & .021 & 127 & 54 & $0 / 4$ \\
\hline Sham & 24 & 5 & .00 & .00 & .026 & .002 & .261 & .045 & .674 & .016 & 162 & 36 & $0 / 5$ \\
\hline
\end{tabular}

*Total stabilimeter counts in 15-min session.

**Pooled values for VMH and LH sham lesions.

Across all groups, an apparent tendency for medial lesions to produce more ulcers (mean $=2.73 \pm .82$ ) than lateral lesions (mean $=1.40 \pm .67$ ) was not shown by an independent $t$ test to be statistically significant $[\mathrm{t}(19)=1.24, \mathrm{p}>.10]$.

Weights of adrenals, thymus, and spleen are included in Table 1. A trend was observed toward slightly increased weights for adrenals and spleen in the VMH group and more noticeably toward decreased thymus weight in both VMH and $\mathrm{LH}$ groups over $24 \mathrm{~h}$. However, the analyses of variance failed to indicate any significant differences between lesioned and control groups in terms of adrenals, thymus, and spleen weights at any of the intervals tested (all ps > .10).

In addition to ulceration, postoperative motor activity levels accounted for significant differences between lesioned and control animals. Independent t tests indicated that the lesioned groups differed significantly from controls [for $\mathrm{VMH}, \mathrm{t}(24)=22.33$ for pooled test and $t(8)=4.12$ for single-group test; for LH, $t(23)=3.98$ for pooled test and $t(6)=6.01$ for single-group test; all ps $<.001$ ] but not from each other $[\mathrm{t}(19)=.95$ for pooled test and $\mathrm{t}(4)=.29$ for single-group test; ps $>.1$ ]. At 8 and $24 \mathrm{~h}$, no significant differences among lesioned or control groups were observed on the activity measure $(t<1.00$, $\mathrm{p}>.1$, in all cases).

\section{Discussion}

These results demonstrate that both lateral and medial lesions can produce stomach ulcers as early as $4 \mathrm{~h}$ after the lesions are made. The fact that ulcers induced by medial and lateral hypothalamic lesions develop at the same rate would seem to argue against the suggestion (Grijalva et al., 1976; Lindholm et al., 1975) that gastric pathology is a causal factor of significance in LH aphagia, and would be in agreement with more recent evidence presented by Schallert et al. (1977).
The fact that neither hypothalamic lesion produced significant changes in adrenal, thymus, or spleen weights in $24 \mathrm{~h}$ in the present experiment is of interest insofar as it provides an indication, albeit a crude one, that ulcer formation after hypothalamic lesions may be a specific effect rather than the result of general damage, as Selye (1946) suggested.

The 15-min activity tests at 4,8 , and $24 \mathrm{~h}$ suggested an abatement of hyperactivity in both lesioned groups after $4 \mathrm{~h}$. Observation of individual animals also suggested that there might be some correlation between amount of hyperactivity in the first few postoperative hours and the incidence and severity of gastric pathology. This possibility was assessed in the second experiment by continuous monitoring of postoperative activity and quantitative indices of extent and severity of gastric pathology.

A possibly confounding factor in this experiment was the fact that animals were food-deprived prior to the lesions, for food deprivation in itself may produce and/or aggravate stomach ulcers (Gheorghiu, 1975). While it must be noted that starvation ulcers are typically confined to the nonglandular part of the rat stomach while brain-lesion-induced ulcers were found only in the glandular part, it would be desirable to repeat the procedure with nondeprived rats. Also, it would be important to demonstrate directly that the medial lesions which produced ulceration in the present experiment can, indeed, produce hyperphagia that is simultaneous with the gastric pathology, especially since some of the medial lesions in this experiment did extend into lateral areas.

\section{EXPERIMENT 2}

\section{Method}

Animals. Male Wistar rats (Woodlyn Laboratories and High Oak Laboratories, Ontario), with weights between 300 and $480 \mathrm{~g}$, received bilateral anodal lesions in the lateral or ventromedial hypothalamus under sodium pentobarbital anesthesia $(60 \mathrm{mg} / \mathrm{kg})$. Lesion procedures and coordinates were the same as in Experi- 


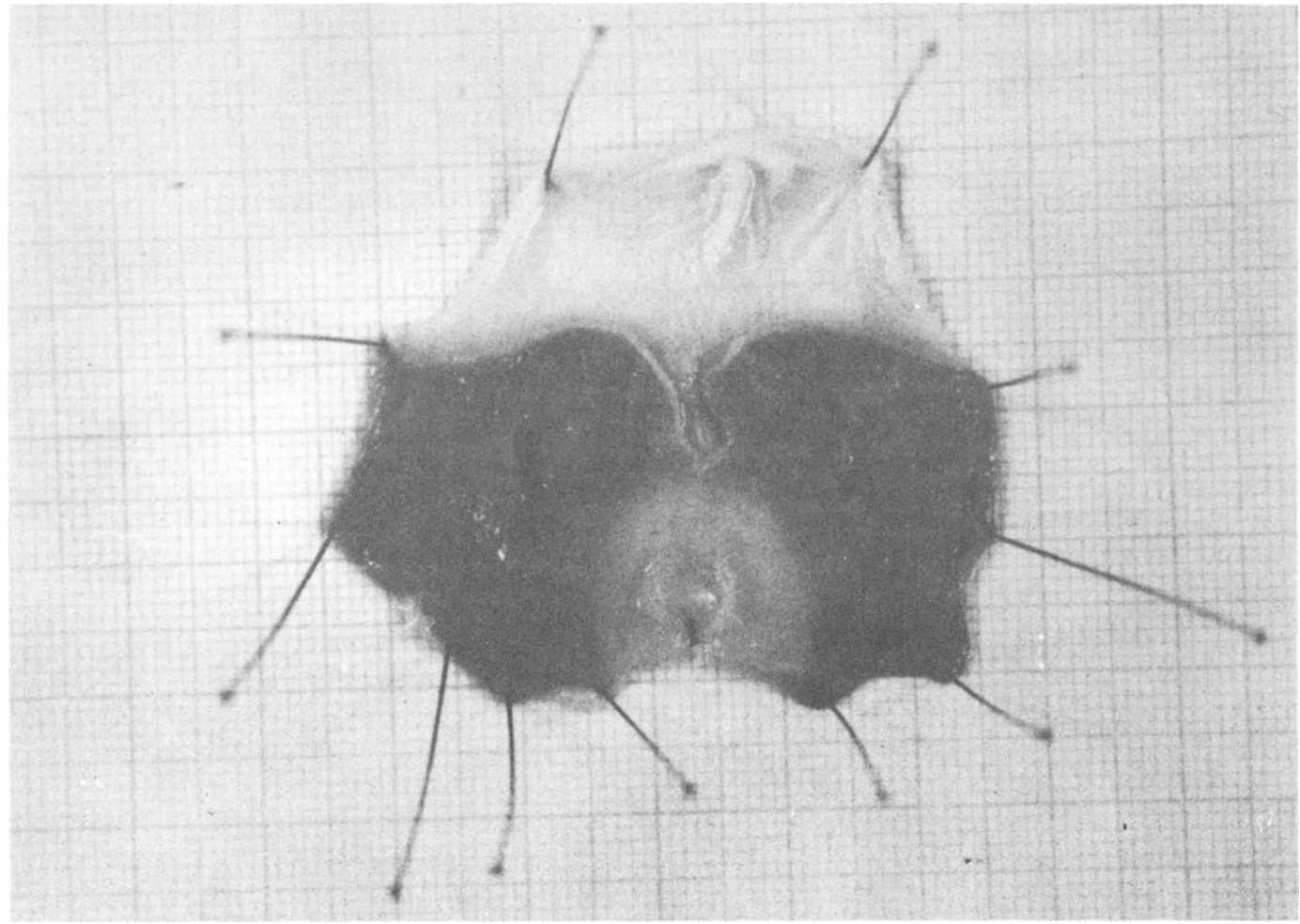

Figure 3. Stomach of a VMH rat showing hemorrhagic ulceration $24 \mathrm{~h}$ after the brain lesion.

ment 1 , except for the lateral coordinates for $\mathrm{VMH}$ lesions: $\pm .6 \mathrm{~mm}$ lateral to the midline was used instead of $.8 \mathrm{~mm}$ in order to minimize damage to the lateral hypothalamic area. Animals had food and water available until the time of surgery.

Immediately after the lesion, animals were placed in $15 \times 30 \times$ $20 \mathrm{~cm}$ boxes mounted on stabilimeters built after the Lafayette Instrument No. 8610 activity platform for continual recording of motor activity. Thirty-three rats received medial lesions and 25 received lateral lesions. Ten control rats were anesthetized and then placed in the activity boxes. No food or water was available for $24 \mathrm{~h}$ after the lesions.

A second group of 18 rats received bilateral medial or lateral hypothalamic lesions, but were allowed to eat and drink after the lesion. To avoid problems of animals choking on dry food, a wet mash, consisting of Teklad pellet powder $(50 \%)$, sugar $(27 \%)$, and corn oil $(23 \%)$, was prepared. Each animal had access to a measured amount of this diet in a glass container fastened to the side of the cage for $24 \mathrm{~h}$ postoperatively. Since it has been observed that $\mathrm{VMH}$ rats often die after consuming great quantities of water, probably due to disruption of the organism's water-solute balance, the animals were given $.85 \%$ saline in graduated bottles (Wishart $\&$ Walls, 1975). Ten control animals were anesthetized and placed in single cages with food and saline. Food and saline consumption was recorded for each animal 6 and $24 \mathrm{~h}$ after the lesions.

In a third group of rats, bilateral lesions were produced in the following extrahypothalamic areas: caudate nucleus (coordinates: +2.2 , $\pm 3.0,6.2$; three rats); nucleus accumbens (coordinates: $+3.4, \pm 1.7,7.0$; three rats); and central gray area (coordinates: $-5.6, \pm .7,5.0$; two rats), using the same lesion procedures $(1-\mathrm{mA}$ anodal dc current for $20 \mathrm{sec})$ as in the hypothalamic lesions. The stomachs of these animals were examined after $24 \mathrm{~h}$, but their postoperative behavior was not monitored in the activity boxes, and for this reason their data were treated separately and not included in the multivariate analyses along with the data for the hypothalamic rats and their controls.
Twenty-four hours after the lesions or injections, all animals were sacrificed with chloroform. The stomachs were removed, and the animals perfused with saline and Formalin. Photographic prints of unstained brain sections were made as described in Experiment 1 . In some instances, the 50-micron sections were projected onto the corresponding plate of the Pellegrino and Cushman atlas (1967) and the contours of the lesion were drawn directly from the projected image. Data for rats with asymmetrical lesions were not used.

Stomachs were inspected immediately after removal. They were washed once in saline, pinned flat onto a styrofoam platform, and examined under a dissecting microscope fitted with a reticle, at $7 \times$ magnification. The length and greatest width of each erosion were measured. Two additional measures were obtained by multiplying the area (length $\times$ width) and length (length + width) of each erosion by the corresponding score on a scale designed to indicate the severity of the pathology observed. Scores were as follows: $0=$ no signs of erosions, ischemia, reddening of the mucosa, dilation of blood capillaries, or localized ischemia; $1=$ visible erosions with ill-defined contours and no signs of hemorrhage; $2=$ erosions with sharply defined contours but no signs of hemorrhage; $3=$ small, shallow erosions with traces of hemorrhage; $4=$ well-defined erosions partially filled or surrounded by hemorrhage; $5=$ well-defined erosions totally filled by hemorrhage.

Since no single measure of stomach pathology seems to be uniformly accepted and used in the literature, multivariate analyses included all of the following variables: number of ulcers per rat, mean ulcer score per rat, total area, total weighted area, total length, and total weighted length, in addition to the total amount of stabilimeter activity in the first $6 \mathrm{~h}$ after the lesions.

\section{Results}

Stomach pathology. The data relative to stomach pathology $24 \mathrm{~h}$ after medial and lateral hypothalamic 
Table 2

Means and Standard Errors for the Seven Variables in Experiment 2

\begin{tabular}{|c|c|c|c|c|c|c|c|c|c|c|c|c|c|c|c|}
\hline \multirow[b]{2}{*}{ Group } & \multirow[b]{2}{*}{$\mathrm{N}$} & \multicolumn{2}{|c|}{$\begin{array}{l}\mathrm{N} \text { of } \\
\text { Ulcers }\end{array}$} & \multicolumn{2}{|c|}{$\begin{array}{l}\text { Mean } \\
\text { Score }\end{array}$} & \multicolumn{2}{|c|}{$\begin{array}{c}\text { Total } \\
\text { Area }\left(\mathrm{mm}^{2}\right)\end{array}$} & \multicolumn{2}{|c|}{$\begin{array}{c}\text { Weighted } \\
\text { Area }\end{array}$} & \multicolumn{2}{|c|}{$\begin{array}{c}\text { Total } \\
\text { Length }(\mathrm{mm})\end{array}$} & \multicolumn{2}{|c|}{$\begin{array}{l}\text { Weighted } \\
\text { Length }\end{array}$} & \multicolumn{2}{|c|}{$\begin{array}{l}\text { 6-H Activity } \\
\text { Counts }\end{array}$} \\
\hline & & $\mathbf{M}$ & SE & $\mathbf{M}$ & SE & $\mathbf{M}$ & $\mathrm{SE}$ & $\mathbf{M}$ & SE & $\mathbf{M}$ & SE & $\mathbf{M}$ & SE & $\mathbf{M}$ & SE \\
\hline VMH & 19 & 4.23 & .82 & 1.10 & .21 & 49.80 & 20.37 & 44.27 & 16.30 & 37.04 & 16.18 & 34.84 & 14.50 & 22818 & 2312 \\
\hline LH & 14 & 2.93 & .95 & 1.59 & .32 & 16.47 & 10.30 & 32.16 & 20.99 & 14.23 & 8.15 & 29.08 & 17.51 & 7836 & 1525 \\
\hline Controls & 10 & .00 & .00 & .00 & .00 & .00 & .00 & .00 & .00 & .00 & .00 & .00 & .00 & 901 & 158 \\
\hline
\end{tabular}

lesions are shown in Table 2. ANOVA comparisons following multivariate and univariate analyses of variance indicated significant differences between lesioned and nonlesioned groups on all seven dependent variables [multivariate $\mathrm{F}(7,34)=15.43, \mathrm{p}<.001$; each univariate $F$ test with $1,40 \mathrm{df}$, all $\mathrm{ps}<.01$ ). Comparison of the medial and lateral groups failed to indicate significant differences on any of the measures of stomach pathology (all ps $>.20$ ), although a trend is apparent in Table 2 for medial lesions to induce more stomach pathology than lateral lesions on all measures.

As in the previous experiment, both types of brain lesion induced stomach pathology that was restricted to the glandular portion of the stomach. Gastric pathology in both hypothalamic groups ranged from ischemia to deep, sharply defined erosions of the stomach with a hemorrhagic base. In many cases, the stomach would contain one or two large, vertically elongated hemorrhagic ulcers medially located in the corpus of the stomach and usually coinciding with a major fold of the mucosa, plus a few smaller erosions scattered about. In other cases, only one or two erosions, often hemorrhagic, were found in an otherwise healthy stomach.

In contrast, none of the extrahypothalamic lesions led to significant gastric pathology after $24 \mathrm{~h}$. Reddening of the stomach mucosa was seen in one of the rats with a lesion in the central gray area; no signs of pathology were seen in the stomachs of rats with lesions in the nucleus accumbens or caudate nucleus.

Figure 4 shows the lesion placements for rats in the medial and lateral hypothalamic groups. Detailed examination of the histological prints failed to reveal any consistency in terms of anterior-posterior or lateral planes in connection with incidence or severity of the ulcers. In the medial group, lesions restricted to the VMH resulted in gastric pathology in 7 of 8 cases. Lesions involving the anterior hypothalamic area produced gastric pathology in 2 out of 2 cases. Two lesions apparently confined to the dorsomedial nucleus did not produce any measurable gastric pathology. Laterally, lesions in the zona incerta/medial lemniscus area produced ulcers in 7 out of 9 cases. Lesions confined to the lateral hypothalamus/medial forebrain bundle produced ulcers in 4 out of 5 cases.

Motor activity. The only variable on which there was a significant difference between medial and lateral groups was the total amount of motor activity in the first $6 \mathrm{~h}$ after the lesion, as measured by stabilimeter counts $[F(1,40)=7.16, p<.001]$. Means and standard errors for this variable are included in Table 2. Independent $t$ tests confirmed that both the medial group $[\mathrm{t}(27)=6.81, \mathrm{p}<.002]$ and the lateral group $[\mathrm{t}(22)=3.81, \mathrm{p}<.002]$ had significantly higher means than the control group on this measure.

While, again, no single ulcerogenic site could be identified within the hypothalamus, postoperative motor activity was found to correlate positively with gastric pathology in this experiment. Rank-order correlations on raw scores and Pearson's productmoment correlations on log-transformed scores indicated significant correlations between total 6-h activity counts and each of the six stomach pathology variables. The $r$ value obtained for correlations between 6-h activity and number of ulcers, mean ulcer score, total area of ulceration, total weighted area, total length were, respectively: $.42, .42 ., .47, .50$, .46 , and.49 ( $\mathrm{p}<.01$ in each case).

Food and saline consumption. Amounts eaten and drunk by rats that had medial and lateral hypothalamic lesions and access to wet mash and saline following surgery are shown in Table 3. Lesion placements for these rats are presented in Figure 5. As illustrated, most of the medial lesions were confined to the VMH; in three rats damage to the ventral premammillary nucleus also occurred. Three of the lesions in the lateral group affected the zona incerta as well as the lateral hypothalamus. In the medial group, over half of the total amounts eaten and drunk in the $24 \mathrm{~h}$ postlesion were ingested in the first $6 \mathrm{~h}$. Independent $\mathrm{t}$ tests confirmed that mean consumption of mash and saline was significantly higher for medial rats than for controls after both 6

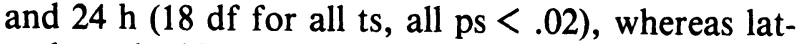
eral rats had lower means than controls at both intervals $(13 \mathrm{df}$, all $\mathrm{ps}<.01)$.

\section{Discussion}

These results confirm and extend the findings of Experiment 1 with respect to the ability of both medial and lateral hypothalamic lesions to induce severe acute stomach ulcers. They also demonstrate that this is not due to food deprivation prior to the 


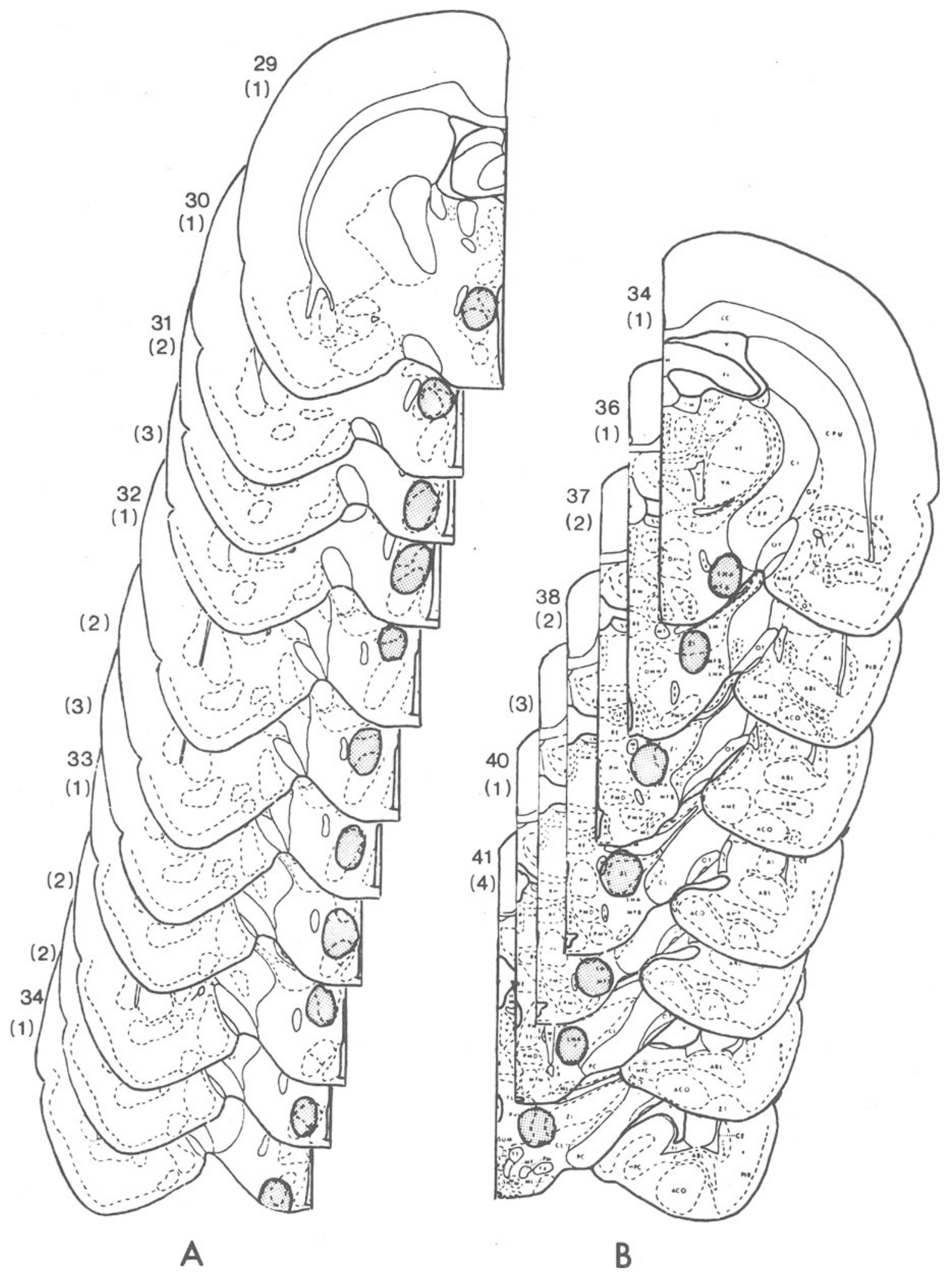

Figure 4. Semidiagramatic reconstruction of lesion placements for rats in the medial (A) and lateral (B) groups tested for activity and ulceration in Experiment 2. Numbers to the left of each section correspond to plates in the Pellegrino and Cushman (1967) atlas. Numbers in parentheses indicate number of animals in each case. 
Table 3

Means and Standard Errors for Food and Saline Consumption After Hypothalamic Lesions

\begin{tabular}{|c|c|c|c|c|c|c|c|c|c|}
\hline \multirow[b]{3}{*}{ Group } & \multirow[b]{3}{*}{$\mathrm{N}$} & \multicolumn{4}{|c|}{ Food Consumption (g) } & \multicolumn{4}{|c|}{ Saline Consumption (ml) } \\
\hline & & \multicolumn{2}{|c|}{$6 \mathrm{H}$} & \multicolumn{2}{|c|}{$24 \mathrm{H}$} & \multicolumn{2}{|c|}{$6 \mathrm{H}$} & \multicolumn{2}{|c|}{$24 \mathrm{H}$} \\
\hline & & $\mathbf{M}$ & SE & $\mathrm{M}$ & SE & $\mathbf{M}$ & SE & $\mathbf{M}$ & SE \\
\hline VMH & 10 & 25.2 & 3.66 & 47.55 & 6.87 & 62.67 & 22.43 & 116.53 & 27.81 \\
\hline LH & 5 & .2 & .21 & 2.3 & 1.13 & 0 & 0 & 0 & 0 \\
\hline Controls & 10 & 3.34 & 1.27 & 16.82 & 1.43 & .5 & .5 & 15.83 & 1.45 \\
\hline
\end{tabular}

lesion. Food deprivation, however, may affect the type of ulcers induced by the lesions, for Schallert et al. (1977) reported ulcers in the nonglandular portion of the stomach of rats deprived of food for more than $24 \mathrm{~h}$ prior to $\mathrm{LH}$ lesions.

The fact that lesions in the nucleus accumbens, caudate nucleus, and central gray area did not result in gastric pathology suggests that the hypothalamic lesions may be affecting central mechanisms involved in ulcer formation more directly than other ulcerinducing agents, including generalized bodily damage.

The observation that medial hypothalamic placements associated with gastric pathology induced voracious eating and drinking starting soon after recovery from anesthesia, while lateral animals consistently refused to eat and drink at that time, constitutes additional evidence against the possibility that $\mathrm{LH}$ feeding deficits result from the concomitant gastric pathology. However, since feeding has a protective effect against some types of ulcers (Cosen \& Mazure, 1975; Mikhail, Gabriel, \& Glavin, 1977), it might be argued that perhaps the immediate lesioninduced feeding of VMH rats (Harrell \& Remley, 1973) usually prevents ulcer formation, while LH rats become chronically aphagic because ulceration is allowed to develop before normal postlesion feeding would resume. We have observed, however, that VMH rats with no postoperative food will readily consume food offered to them $24 \mathrm{~h}$ after the lesion, at a time when ulcers are already fully formed.

\section{GENERAL DISCUSSION}

The reliability of hypothalamic lesions in producing stomach pathology (over $80 \%$ for all hypothalamic lesions) and the rapidity with which ulcers are formed after the lesions (as early as $4 \mathrm{~h}$ ), suggest that this technique may be a more direct induction of the neural conditions related to ulcer formation than are other experimental procedures.

The mechanism or mechanisms involved in the production of hypothalammic lesion-induced ulcers have not been clarified. The fact that in the present experiments comparable gastric pathology was obtained after hypothalamic lesions at several rostrocaudal planes is not consistent with earlier hypoth- eses that brain-lesion-induced ulcers resulted from autonomic imbalance occasioned by lesions of the posterior hypothalamus or by stimulation of the anterior hypothalamus (French et al., 1952). The view that these ulcers are equivalent to those induced by any suddenly developing damage to the body or nervous system was also not supported in the present experiments, for same-size lesions in other parts of the brain failed to induce acute ulceration. In addition, responses such as adrenal enlargement and involution of the thymus and spleen, which are known to occur in response to systemic damage, shock, and other "alarming" agents (Selye, 1946), were not detected after the hypothalamic lesions. On the other hand, ulcers induced by both medial and lateral hypothalamic lesions did resemble ulcers induced by various experimental "stress" procedures in terms of location in the stomach and general appearance (Gheorghiu, 1975; Paré \& Livingston, 1970).

There have been suggestions that some of the acute effects of hypothalamic lesions, for example, hypertension (Reis et al., 1976), hyperactivity (Reis et al., 1976; Whishaw \& Robinson, 1974), and the hyperphagia seen after VMH lesions (Harrell \& Remley, 1973), may be due to irritative effects of anodal iondepositing electrolytic lesions. In other words, these effects might be due to stimulation rather than destruction of brain tissue. On the other hand, ulcer formation has been reported after hypothalamic lesions made with nonirritative techniques such as radio frequency (Luparello, 1967), cathodal electrolytic lesions (Schallert et al., 1977), and suction and probe puncture (Watts \& Fulton, 1935). In this context, the moderate correlations between motor activity and stomach ulceration in the present experiments may have been a function of the type of lesioning current, for cathodal lesions have been reported to cause ulceration (Schallert et al., 1977) but not hyperactivity (Whishaw \& Robinson, 1974). However, since in these two studies the ulcer-rating technique (Schallert et al., 1977) and the technique used for measuring motor activity (Whishaw \& Robinson, 1974) were quite different from the ones used in the present study, further investigation of this point would seem to be justified.

The long-term hyperphagia and weight gain which 


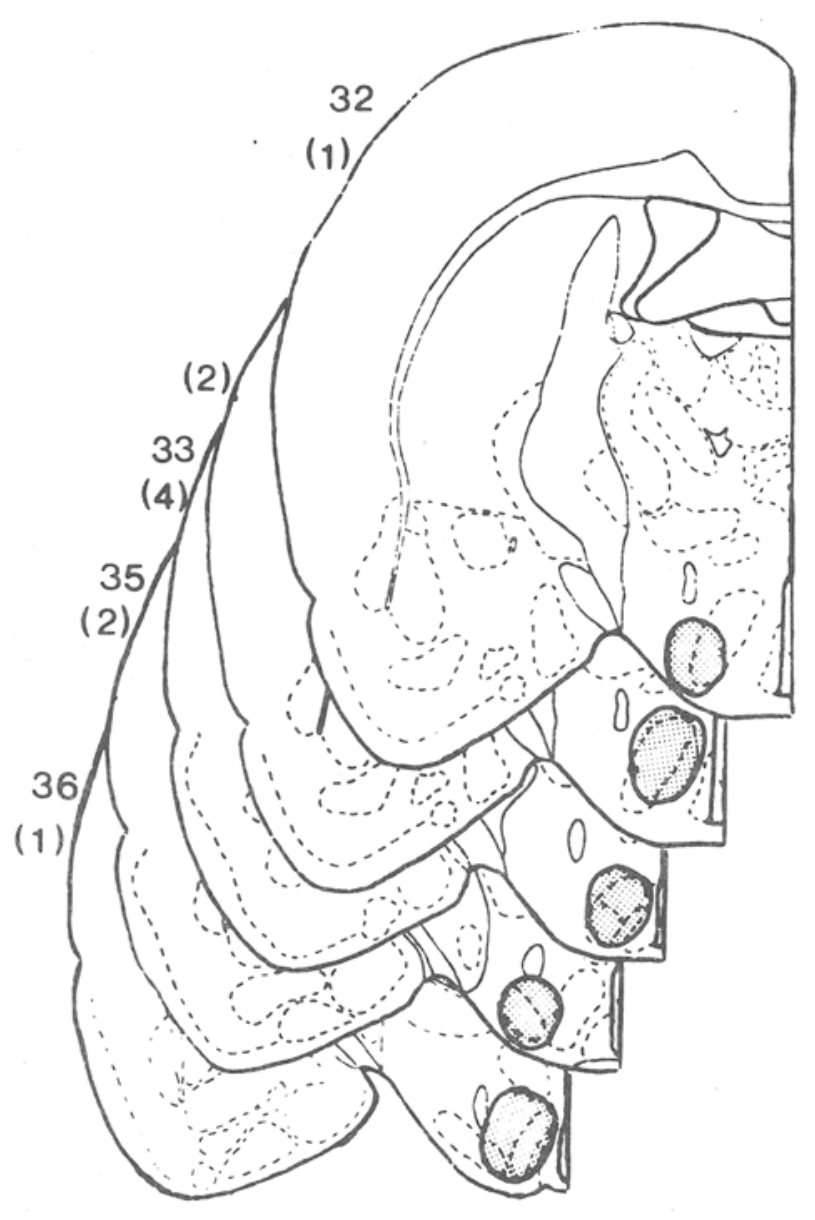

A

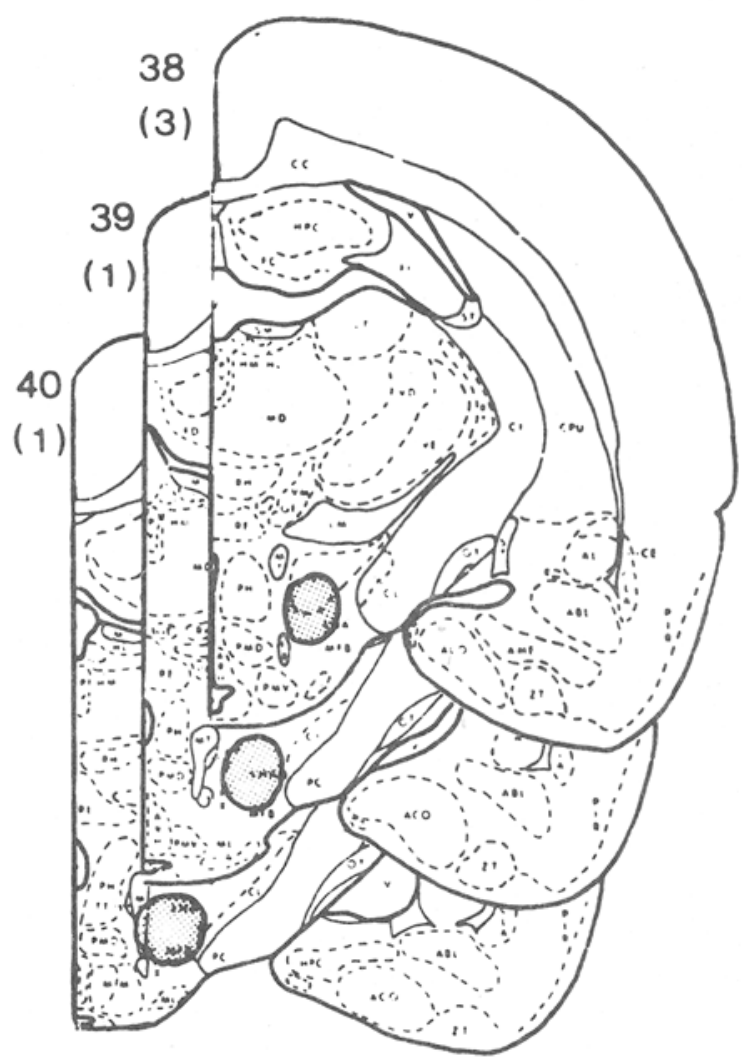

B

Figure 5. Semidiagramatic reconstruction of lesion placements for rats in medial (A) and lateral (B) groups tested for food and saline consumption in Experiment 2. See legend for Figure 4.

are characteristic of the classic VMH syndrome have also been observed in this laboratory with the lesion procedure used in the present acute experiments. However, insofar as acute and chronic effects of hypothalamic lesions on feeding may involve different mechanisms (Harrell \& Remley, 1973), the implications of the present findings on feeding and gastric pathology should be limited to the demonstration that stomach ulceration can occur concomitantly with aphagia or hyperphagia, whether these acute feeding disturbances are caused by stimulation, destruction of tissue, or any other mechanism.

\section{REFERENCES}

Anand, B. K., \& Brobeck, J. R. Hypothalamic control of food intake in rats and cats. The Yale Journal of Biology and Medicine, 1951, 24, 123-140.
Anderson, E., \& Haymaker, W. Breakthroughs in hypothalamic and pituitary research. In D. F. Swab \& J. P. Scade (Eds.), Integrative hypothalamic activity (Progress in Brain Research, Vol. 41). Amsterdam: Elsevier, 1974.

Cosen, N., \& Mazure, P. Restraint-induced ulcer with feeding: A test for pharmacological studies. In T. Gheorghiu (Ed.), Experimental ulcer. Baden-Baden, West Germany: Gerhard Wizstrock, 1975.

Cushing, H. Peptic ulcers and the interbrain. Surgery, Gynecology and Obstetrics, 1932, 55, 1-34.

French, J. D., Porter, R. W., von Amerongen, F. K., \& RANEY, R. B. Gastrointestinal hemorrhage and ulceration associated with intracranial lesions. Surgery, 1952, 32, 395-407.

GheorghiU, T. The experimental ulcer: An introduction. In T. Gheorghiu (Ed.), Experimental ulcer. Baden-Baden, West Germany: Gerhard Witzstrock, 1975.

Grijalva, C. V., Lindholm, E., Schallert, T., \& Bucknell, E. Gastric pathology and aphagia following lateral hypothalamic lesions in rats: Effects of preoperative weight reduction. Journal of Comparative and Physiological Psychology, 1976, 90, 505-519.

HarRell, E. H., \& Remley, N. R. The immediate development 
of behavioral and biochemical changes following ventromedial hypothalamic lesions in rats. Behavioral Biology, 1973, 9, 49-63.

Hoff, E. C., \& Sheehan, D. Experimental gastric erosions following hypothalamic lesions in monkeys. American Journal of Pathology, 1935, 11, 789-802.

Lindholm, E., Shumway, G. S., Grijalva, C. V., Schallert, T., \& RUPPEL, M. Gastric pathology produced by hypothalamic lesions in rats. Physiology \& Behavior, 1975, 14, 165-169.

Long, D. M., Leonard, A. S., \& French, L. A. Hypothalamus and gastric ulceration. I. Gastric effects of hypothalamic lesions. Archives of Neurology, 1962, 7, 13-21.

Luparello, T. J. Neurogenic gastroduodenal erosions in the guinea pig. Journal of Psychosomatic Research, 1967, 11, 299-306.

Maire, F. W., \& Patton, H. D. Hyperactivity and pulmonary edema from rostral hypothalamic lesions in rats. American Journal of Physiology, 1954, 178, 315-320.

McGinTY, D. J. Somnolence, recovery and hyposomnia following ventromedial diencephalic lesions in the rat. Electroencephalography and Clinical Neurophysiology, 1969, 26, 70-79.

Mikhail, A. A., Gabriel, R. M., \& Glavin, G. B. Ulcer reduction by nonnutritive bulk in pylorus-ligated rats. Physiology \& Behavior, 1977, 19, 437-439.

Paré, W. P., \& Livingston, A., Jr. Brain norepinephrine and stomach ulcers in rats exposed to chronic conflict. Physiology \& Behavior, 1970, 5, 215-220.

Pellegrino, L. J., \& Cushman, A. J. A stereotaxic atlas of the rat brain. New York: Appleton-Century-Crofts, 1967.
Reis, D. J., Gauthier, P., \& Nathan, M. A. Hypertension, adrenal catecholamine release, pulmonary edema and behavioral excitement elicited from the anterior hypothalamus in rats. In E. Usdin, R. Kvetnansky, \& I. J. Kopin (Eds.), Catecholamines and stress. Oxford: Pergamon Press, 1976.

Schallert, T., Whishaw, I. Q., \& Flannigan, K. P. Gastric pathology and feeding deficits induced by hypothalamic damage in rats: Effects of lesion type, size and placement. Journal of Comparative and Physiological Psychology, 1977, 91, 598-610.

SELYE, H. The general adaptation syndrome and the diseases of adaptation. Journal of Clinical Endocrinology, 1946, 6, 117-230.

Teitelbaum, P., \& Epstein, A. M. The lateral hypothalamic syndrome: Recovery of feeding after lateral hypothalamic lesions. Psychological Review, 1962, 69, 74-90.

Watts, J. W., \& Fulton, J. F. The effect of lesions of the hypothalamus upon the gastro-intestinal tract and heart in monkeys. Annals of Surgery, 1935, 101, 363-372.

Whishaw, I. Q., \& Robinson, T. E. Comparison of anodal and cathodal lesions and metal deposition in eliciting postoperative locomotion in the rat. Physiology \& Behavior, 1974, 13, 539-551.

Wishart, T. B., \& Walls, E. K. Water intoxication and death following hypothalamic lesions in the rat. Physiology \& Behavior, 1975, 15, 377-379.

(Received for publication December 4, 1979; revision accepted January 23, 1980.) 